\title{
Initial Treatment: Prostaglandin Analog or Selective Laser Trabeculoplasty
}

\section{Colin I Clement}

\begin{abstract}
Prostaglandin analogs ( $P G A$ ) have been the initial treatment of choice in many patients with glaucoma. However, there is an increasing awareness that non adherence and dis ruption of the ocular surface may limit P G A utility and tolerability respectively in some patients. In an eye with an open iridocorneal angle, these issues can potentially be addressed with the use of laser trabeculoplasty (LT). This therapy can achieve long-term intraocular pressure reduction following 1 to 2 treatment sessions without the ongoing need to apply medication (and preservatives) to the ocular surface. Whether PGAs or LT should be used in a given individual will also be influenced by other important factors including efficacy, response rate, tolerability, complications, cost and accessibility. This review examines these issues in relation to the initiation of primary therapy.
\end{abstract}

Keywords: Prostaglandin analogs, Selective laser trabeculoplasty, Glaucoma therapy, Compliance.

How to cite this article: Clement $\mathrm{Cl}$. Initial Treatment: Prostaglandin Analog of Selective Laser Trabeculoplasty. J Current Glau Prac 2012;6(3):99-103.

\section{Source of support $\mathrm{Nil}$}

Conflict of interest: None declared

\section{INTRODUCTION}

Prostaglandin analogs (PGA) have been the centerpiece of initial glaucoma management for many years due to their efficacy, once daily dosing and favorable side effect profile relative to other medications. In contrast, laser trabeculoplasty (LT) has had a less defined role in glaucoma management since its introduction in the $1980 \mathrm{~s}^{1}{ }^{1} \mathrm{M}$ any have used LT as a stopgap measure to avoid or delay surgery in eyes that are failing medical therapy. This was reflected in the study design for the advanced glaucoma intervention study (A GIS), ${ }^{2}$ where patients with advanced glaucoma were randomized to argon $L T$ ( $A L T)$ followed by sequential trabeculectomies or trabeculectomy-A LT-trabeculectomy. Since then, $\mathrm{LT}$ has al so been utilized in individuals intolerant of topical medications or in whom medication use is not practical (e.g. severe arthritis, restricting dexterity, chronic nonadherence).

However, LT has evolved from its initial development. Selective $L T(S L T)$ represents a change in terms of ease of treatment (less specific target area, no need for posttreatment anti-inflammatory medication) although any difference in outcome or repeatability remains controversial and is probably not significant. ${ }^{3}$ A long with this has been an increasing awareness that glaucoma medications are often not used as intended and may severely compromise the health of the ocular surface. For these reasons, trabeculoplasty may be a better option for initial treatment in some patients.

\section{Efficacy and Response Rates}

\section{Head-to-Head Comparison}

Theintraocular pressure (IOP) low ering effect of latanoprost has been prospectively assessed against $90^{\circ}, 180^{\circ}$ and $360^{\circ}$ SLT in a population with high baseline IOP. ${ }^{4}$ The most effective $S L T$ regimen, $360^{\circ}$ treatment, resulted in $>20 \%$ IOP reduction in $82 \%$ of eyes and $>30 \%$ in $59 \%$ of eyes. This was less than latanoprost in which IOP reduction $>20 \%$ occurred in $90 \%$ of eyes and $>30 \%$ in $78 \%$ of eyes, although this did notreach statistical significance. A similar prospectivestudy ${ }^{5}$ compared $360^{\circ} \mathrm{SLT}$ with PGA s with 6 follow-up visits over 12 months. Outcomewas measured in terms of reaching target IOP (as per thecollaborativeinitial glaucomatreatmentstudy) and number of additional steps needed to achieve target IOP. From a mean baseline of 24.5 to $24.7 \mathrm{~mm} \mathrm{Hg}$, there was no significant difference in IOP reduction between the two strategies but fewer interventions were needed in the SLT compared to medical group (11 vs $27 \%$ ).

The soon to be released SLT/M ED study, a prospective randomized trial of SLT vs prostaglandins, is expected to show equal efficacy after 12 months.

\section{Nonresponders}

Response to therapy may be defined as reaching target or desired IOP. The target IOP will differ depending on clinical need but a reduction of $20 \%$ is usually a minimum. M ost studies report this over the short term and ignore the effects on other aspects of IOP, such as peak IOP or circadian IOP fluctuation. Despite this, target IOP and measuring response rates does provide valuable information about treatment efficacy.

The above-mentioned study by $\mathrm{N}$ agar et al ${ }^{4}$ suggests that the nonresponder rate (defined as an IOP reduction of less than $20 \%$ from baseline) is approximately double for SLT compared to latanoprost (18 vs $10 \%$ ). However, $\mathrm{Mcl}$ lraith et $\mathrm{al}^{6}$ did not report such a difference in a prospective comparison of SLT and latanoprost. Instead, they found similar response rates in both groups after 12 months (>20\% reduction: $83 \%$ SLT, $84 \%$ latanoprost). 
Ones overall impression is that the initial PGA non response rate is higher in these two studies than has been reported elsewhere. However, it is important to consider what happens over the longer term, when infact most studies report only short-term data (up to 3 months). ${ }^{7}$ There are in fact few studies that have examined PGA efficacy beyond 6 months. Of the few that extend for 6 months or more, there is suggestion of reducing response rates over time. A $<20 \%$ reduction in IOP was reported in approximately $13 \%$ of 128 eyes after 6 months of once daily latanoprost treatment in a multicenter randomized trial. ${ }^{8} \mathrm{~W}$ ith followup after 12 months of PGA treatment, nonresponders account for as much as 15 to $25 \%$ and it continues to decline from there. ${ }^{9}$ It is not clear whether these outcomes are subject to the same influence of nonadherence as in reallife; potentially these results could be worse.

\section{Duration of Treatment E ffect}

The above-mentioned studies indicate that the PGA effect on IOP may wear off over time in some eyes. The 36-month study by F riström and $U$ usital $0^{9}$ suggests that treatmentfailure on PGA s is up to $40 \%$ by the end of this period. However, their definition of treatment failure was based on change to treatment that may occur even when IOP is low relative to baseline. Therefore, this likely over-represents treatment failure compared to a definition of $I 0 P<20 \%$ from baseline.

The long-term benefit of SLT as primary therapy for primary open angle glaucoma (POAG) and pseudoexfoliation glaucoma (PXFG) has been reported in a small prospective study..$^{10}$ Treatment failure was defined as a return to baseline IOP (within $3 \mathrm{~mm} \mathrm{Hg}$ ) or initiation of further IOP-lowering treatment. B aseline IOP was 23.2 $\mathrm{mm} \mathrm{Hg}(\mathrm{n}=19)$ for eyes with POAG and $25.5 \mathrm{~mm} \mathrm{Hg}$ $(n=18)$ for eyes with PXFG. M ean follow-up was 27.1 months (range 6-42 months) for POAG and 20.4 months (range 3-42 months) for PXFG with considerable loss to follow-up in both groups for analysis beyond 30 months (42\% POA G; $56 \%$ PXFG). By the 30 to 42 months analysis, mean IOP reduction was $5.7 \mathrm{~mm} \mathrm{Hg} \mathrm{(24.6 \% )} \mathrm{for} \mathrm{POA} \mathrm{G}$ and $5.5 \mathrm{~mm} \mathrm{Hg}(21.6 \%)$ for PX FG. By 30 months, failures accounted for $16 \%$ of POAG and $22 \%$ of PXFG.

\section{Predictors of Outcome}

Several studies point to baseline IOP as a predictor of IOP reduction after $S L T .{ }^{11,12}$ It is therefore not surprising that the efficacy of SLT in OA G with statistical ly normal IOP is not as good. EI Mallah et $\mathrm{al}^{13}$ retrospectively analyzed response to SLT in 31 eyes of 18 patients with $10 P<22$ $\mathrm{mm} \mathrm{Hg}$. Mean IOP reduction was $14.7 \%$ from a baseline IOP of $14.3 \mathrm{~mm} \mathrm{Hg}$. The number of eyes achieving a 20 or
$30 \% 10 \mathrm{P}$ reduction was not reported and cannot be deduced from the presenting data.

Similarly, PGAs are less effective, when baseline IOP is less than $21 \mathrm{~mm} \mathrm{H} \mathrm{g.}{ }^{14}$ Further, T sunda et al ${ }^{15}$ have show $\mathrm{n}$ that baseline IOPs $<15 \mathrm{~mm} \mathrm{Hg}$ are associated with a smaller IOP reduction than IOPs in the 16 to $21 \mathrm{~mm} \mathrm{Hg}$ range. To date, there are no studies that specifically compare IOP reduction in normal tension glaucoma between SLT and medication.

A dherence to therapy is directly related to treatment response meaning factors that influence adherence will have a knock on effect. M ultiple risk factors for nonadherence have been identified and include personality type (depression, hypochondiasis), ethnicity (Afro-Caribbean, Latino), socioeconomic status (income, education, literacy), age, number of eye diseases and disease understanding. ${ }^{16,17}$ For this reason, LT may offer a better primary option in these patients. This is particularly so given interventions, such as telephone reminders and tailored print materials do not improve adherence rates ${ }^{18}$ and may be impractical for a health service to provide given the burden of glaucoma in the community.

\section{Adherence}

One obvious advantage of $L T$ is its ability to overcome the issue of nonadherence. N onadherence remains a significant issue with glaucoma medication and this is certainly true for PGA use. A dherence to PGAs, regardless of which type, is estimated to be approximately $30 \%$ after 12 months. ${ }^{19}$ A dherence to medical treatment may be overrepresented in clinical trials due to the nature of the intervention and monitoring and al so the patient characteristics of individuals willing to participate in trials. This raises the possibility that $I O P$ reduction and any benefit derived from this in terms of visual performance may not be as good as is reported in the literature.

\section{Circadian IOP Fluctuation}

There is increasing interest in IOP fluctuation and the role this plays in glaucoma pathogenesis. ${ }^{20}$ As such, it is interesting and important to consider treatment effect in terms of IOP fluctuation in addition to mean IOP reduction, percentage IOP reduction and nonresponse rates.

A number of studies have tried to assess the influence SLT has on IOP fluctuation. Prasad et al ${ }^{21}$ have examined the change in intervisit IOP fluctuation after 180 or $360^{\circ}$ $\mathrm{SLT}$. Their findings suggest intervisit IOP fluctuation is less following $360^{\circ}$ treatment (IOP change $<2 \mathrm{~mm} \mathrm{Hg}$; $86 \%$ ) compared with $180^{\circ}$ treatment (IOP change $<2 \mathrm{~mm}$ $\mathrm{Hg} ; 52 \%)$ but as intervisit fluctuation was not measured 
Initial Treatment: Prostaglandin Analog or Selective Laser Trabeculoplasty

before treatment, no comment may be made about the overall treatment effect. The effect of SLT on diurnal IOP curves has been prospectively assessed. ${ }^{22}$ Twenty-six eyes not receiving medical therapy underwent $360^{\circ} \mathrm{SLT}$ then were subjected to repeat diurnal IOP curves at 3 and 6 months following. Interestingly, not a single eye achieved a mean diurnal IOP reduction of $>20 \%$ in the 6 months of followup. Sixteen of 26 eyes were commenced on supplementary medical therapy because $I O P$ reduction was thought to be insufficient. The remaining 10 eyes displayed a modest nonsignificant change in mean IOP after SLT $(19.3 \pm 1.4 \mathrm{~mm} \mathrm{Hg}$ vs $18.6 \pm 2.0 \mathrm{~mm} \mathrm{Hg})$ but a significant reduction in diurnal IOP fluctuation (7.2 \pm $2.3 \mathrm{~mm} \mathrm{Hg}$ vs $5.0 \pm 1.7 \mathrm{~mm} \mathrm{Hg}, \mathrm{p}=0.004$ ).

The effect of latanoprost on intervisit IOP fluctuation has been reported. Following 6 months treatment, the rate of high fluctuation (defined as IOP $>6 \mathrm{~mm} \mathrm{Hg}$ ) reduced significantly from 22 to $6 \%$. ${ }^{23}$

A direct comparison between latanoprost and SLT suggests PGAS may dampen IOP fluctuation more effectively. ${ }^{24}$ Comparison of diurnal IOP curves before and 6 months after treatment showed both strategies impact IOP fluctuation. SLT reduced IOP fluctuation by $41 \%$ from a mean of $5.5 \pm 2.7 \mathrm{~mm} \mathrm{Hg}$. By comparison, latanoprost reduced IOP fluctuation by $64 \%$ from a baseline of $5.7 \pm$ $2.1 \mathrm{~mm} \mathrm{Hg}$; the difference between groups was significant $(p=0.0444)$. Successful reduction in IOP fluctuation (defined as at least a $50 \%$ reduction from baseline) was achieved more often following latanoprost therapy (83\%) compared to SLT $(50 \%)$.

\section{Side Effects and Complications}

Side effects reported following initiation of topical prostaglandins are extensive but are rarely severe. ${ }^{25}$ W ell known side effects, include conjunctival hyperemia, hypertrichosis, iris hyperpigmentation and increased periocular skin pigmentation. Others include pruritis, cataract, eyelid edema, foreign body sensation and eye pain. In addition, topical glaucoma medications, including prostaglandin analogs are associated with an increased rate of ocular surface disease (OSD). ${ }^{26,27}$

Complications after SLT are few. The commonest is probably mild anterior chamber inflammation that is transient and requires no treatment $\left(48 \%, \mathrm{M}\right.$ cllraith et al ${ }^{6}$ $83 \%$, L atina et $\mathrm{al}^{28}$ ). IOP spikes of 5 or $8 \mathrm{~mm} \mathrm{H}$ g have been reported in 25 and $9 \%$ of treated eyes respectively (Latina et $\left.\mathrm{al}^{28}\right)$, how ever, none of these persisted beyond 24 hours. Comparable rates of IOP elevation after SLT have been

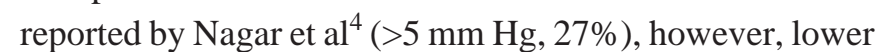
rates are reported in other studies by $\mathrm{Damji}$ et al ${ }^{29}$
( $>6 \mathrm{~mm} \mathrm{Hg}, 4.5 \%$ ) and Lai et al ( $>5 \mathrm{~mm} \mathrm{Hg}, 10.3 \%$ ). Ocular discomfort is sometimes reported following SL T $(15 \%$, L atina et al, ${ }^{28} 39 \%, N$ agar et $\mathrm{al}^{4}$ ) but this effect does not last.

\section{Cost and Availability}

The cost of treating with medications or SLT has recently been reported. ${ }^{30}$ This analysis using data from the USA looked at cost from a patient perspective assuming that both eyes received treatment, SL T was applied to $360^{\circ}$ in a single session and SLT was associated with posttreatment uveitis and IOP spikes in 50 and $27 \%$ respectively. They found the cost of SLT equalled branded PGA s after 6.3 to 6.8 months of treatment and generic latanoprost by 13.1 months. Therefore, it was concluded that if SLT is applied every 6 to 12 months, it maintains cost equivalence with PGA eyes drops. A s IOP reduction is maintained beyond 12 months in many patients without the need for further intervention, SLT may actually be a more affordable option.

This analysis did not model for the costs of additional glaucoma therapy, including other medical treatment, complications after SLT or the need for glaucoma surgery. It also did not take into account the cost of patient transport and repeat visits nor the effect medical treatment has on OSD. B oth medical treatment and SLT costs may be affected by these variables. However, this analysis does highlight the potential cost savings of SLT treatment in individuals that display an extended response to treatment.

A $n$ attempt has been made to take these extra factors into account. U sing M arkov mathematical modeling, Stein et al ${ }^{31}$ have attempted to estimate the cost comparison over 25 years of starting a patient with mild glaucoma on medical therapy verses $L T$. The model takes into account the progressive and incremental nature of glaucoma and also the cost of assessment, annual supply of medications, laser or incisional surgery, accessing low-vision services as well as complications and adverse events. It was concluded, when nonadherence is taken into account, that $L T$ is more economical.

\section{Patient Limitations}

SLT cannot be performed in closed or very narrow angles whereas this does not prevent the use of medications. There may be other physical limitations that prevent the use of SLT, including severe kyphosis, ankylosing spondylosis, torticollis or cervical arthritis preventing head placement on the laser unit. H ead tremor prevents accurate placement of the laser treatment and eyes that are deeply recessed or have narrow palpebral apertures sometimes make gonioscopy lens placement difficult. This is also true in patients with moderate to severe blepharospasm. 


\section{SUMMARY}

Data on the comparative efficacy of SLT and PGA therapy for initial IOP lowering is limited although the forth coming SLT/MED study will in part address this knowledge gap. Currently it appears both treatments have similar efficacy but further studies are needed to definitively answer this question. In the intermediate to long term, SLT may have the edge over PGA s in terms of cost of treatment and is an important consideration as the burden of glaucoma increases. SLT has a number of advantages in the initial management of open-angle glaucoma or ocular hypertension, including its ability to overcome the significant issue of treatment nonadherence that is seen with topical medical treatments. SLT reduces the burden of daily medical treatment; this may be more detrimental to qual ity of life than the condition itself. However, in a condition that is often asymptomatic, medications may have an important role to play in terms of reminding the patient about their condition and the need for vigilance. There is a risk that patients may perceive $S L T$ to be a definitive treatment resulting in complacency with regard to ongoing assessment. Further, PGA s may have greater benefits in terms of their effect on circadian IOP changes. However, our understanding of how this influences glaucoma progression is still evolving so the significance of this effect is not yet known. There are patient groups that are more suited to either treatment and the ultimate decision requires the input of both physician and patient. Patientfactors, past experience and local resources should all be considered, when offering initial therapy.

\section{REFERENCES}

1. Wise JB, Witter SL. A rgon laser therapy for open-angle glaucoma: A pilot study. A rch Ophthalmol 1979;97:319-22.

2. The A GIS investigators. The A dvanced Glaucoma I ntervention Study (A GIS): 1. Study design and methods and baseline characteristics of study patients. Contr Clin Trials 1994;15:299325.

3. Samples JR, Singh K, Lin SC, Francis BA, Hodapp E, J ampel HD , Smith SD. L aser trabeculoplasty for open-angle glaucoma: A report by the American Academy of Ophthalmology. Ophthalmology 2011 Nov;118(11):2296-302.

4. Nagar M, O gunyomade A, O'B rart DPS, H owes F, M arshall J . A randomised, prospective study comparing selective laser trabeculoplasty with latanoprost for the control of intraocular pressure in ocular hypertension and open angle glaucoma. B r J Ophthalmol 2005;89:1413-17.

5. Katz LJ, Steinmann WC, Kabir A, M olineaux J, Wizov SS, $M$ arcellino $G$. Selective laser trabeculoplasty versus medical therapy as initial treatment of glaucoma: A prospective, randomized trial. J Glaucoma 2011, DOI:10.1097/IJ G.0b013e $318218287 f$
6. M cllraith I, Strasfeld M, Colev G, Hutnik CM. Selective laser trabeculoplasty as initial and adjunctive treatment for open-angle glaucoma. J Glaucoma 2006;15:124-30.

7. A ptel F, Cucherat M, Denis P. Efficacy and tolerability of prostaglandin analogues. A meta-analysis of randomized controlled clinical trials. J Glaucoma 2008;17:667-73.

8. Camras CB, Hedman K. US latanoprost study group. Rate of response to latanoprost or timolol in patients with ocular hypertension or glaucoma. J Glaucoma 2003;12:466-69.

9. Friström B, U usitalo H. A randomized, 36-month, postmarketing efficacy and tolerability study in Sweden and Finland of latanoprost versus non-prostaglandin therapy in patients with glaucoma or ocular hypertension. A cta Ophthalmologica 2010;88:37-43.

10. Shazly TA , Smith J, Latina M A . L ong-term safety and efficacy of selective laser trabeculoplasty as primary therapy for the treatment of pseudoexfoliation glaucoma compared with primary open-angle glaucoma. Clinical O phthalmology 2011;5:5-10.

11. M ao AJ, Pan X J, M cllraith I, Strasfeld M, Colev G, Hutnik C. Development of a prediction rule to estimate the probability of acceptable intraocular pressure reduction after selective laser trabeculoplasty in open-angl e glaucoma and ocular hypertension. J Glaucoma 2008;17:449-54.

12. A yala $\mathrm{M}, \mathrm{Chen} \mathrm{E}$. Predictive factors of success in selectivelaser trabeculoplasty (SLT) treatment. Clin Ophthalmol 2011;5: 573-76.

13. EI M allah M K, Walsh M M , Stinnett SS, A srani SG. Selective laser trabeculoplasty reduces mean IOP and IOP variation in normal tension glaucoma patients. Clinical Ophthalmology 2010;4:889-93.

14. Cheng JW, Cai JP, W ei RL. M eta-analysis of medical intervention for normal tension glaucoma. Ophthalmology 2009;116:1243-49.

15. T suda M, A ndo A, M atsuyama K, Otsuji T, Fukui C, M aenishi $\mathrm{N}$, et al. Intraocular pressure (IOP) reduction by latanoprost in Japanese normal tension glaucoma patients over a five-year period stratified by presenting IOP. J Ocul Pharmacol Ther 2009;25:441-45.

16. D reer LE, Girkin C, M ansberger SL. D eterminants of medication adherence to topical glaucoma therapy. J Glaucoma 2012;21:234-40.

17. M urakami $Y, L$ ee B W , D uncan $M, K$ ao A , H uang J $Y$, Singh $K$, $\mathrm{L}$ in SC. Racial and ethnic disparities in adherence to glaucoma follow-up visits in a county hospital population. A rch Ophthalmol $2011 \mathrm{~J} \mathrm{ul;129(7):872-78.}$

18. Glanz K, Beck AD, B undy L, Primo S, Lynn M J, Cleveland J, et al. Impact of a heal th communication intervention to improve glaucoma treatment adherence: R esults of the interactive study to increase glaucoma adherence to treatment trial results of the I-sight trial. A rch Ophthalmol 2012;11:1-7.

19. Wilensky J, Fiscella RG, Carlson AM, M orris LS, Walt J. $M$ easurement of persistence and adherence to regimens of IOPlowering glaucoma medications using pharmacy claims data. A m J Ophthalmol 2006;141:S28-33.

20. Caprioli J, V arma R. Intraocular pressure: Modulation as treatment for glaucoma. A m J O phthalmol 2011;152:340-44.

21. Prasad N, M urthy S, Dagianis J J, L atina M A. A comparison of the intervisit intraocular pressure fluctuation after 180 and 360 
degrees of selective laser trabeculoplasty as a primary therapy in primary open angle glaucoma and ocular hypertension. J Glaucoma 2009;18:157-60.

22. Kóthy $P, T$ óth $M, H$ olló $G$. Influence of selective laser trabeculoplasty on 24-hour diurnal intraocular pressure fluctuation in primary open-angle glaucoma: A pilot study. Ophthalmic Surg Lasers Imaging 2010;41:342-47.

23. Varma R, Lie-J u H, Grunden JW, B ean GW, Sultan M B. A ssessing the efficacy of latanoprost vs timolol using an alternate efficacy parameter: The intervisit intraocular pressure range. A m J Ophthalmol 2009;148:221-26.

24. Nagar M, Luhishi E, Shah N. Intraocular pressure control and fluctuation: The effect of treatment with selective laser trabeculoplasty. Br J O phthalmol 2009;93:497-501.

25. Uusitalo H, Pillunat LE, Ropo A. Efficacy and safety of tafloprost $0.0015 \%$ versus latanoprost $0.005 \%$ eye drops in openangle glaucoma and ocular hypertension: 24-month results of a randomized, double masked phase III study. Acta Ophthalmologica 2010;88:12-19.

26. Katz G, Springs $\mathrm{Cl}$, Craven ER, M ontecchi-Palmer M . O cular surface disease in patients with glaucoma or ocular hypertension treated with B A K - preserved latanoprost or BA K -free travoprost. Clin Ophthalmol 2010;4:1253-61.
27. Skalicky SE, Goldberg I, M cCluskey P. O cular surface disease and quality of life in patients with glaucoma. A m J Ophthalmol 2012;153:1-9.

28. L atina MA, Sibayan SA, Shin DH, et al. Q-switched $532 \mathrm{~nm}$ $\mathrm{Nd}$ :Y A G laser trabeculoplasty (selective laser trabeculoplasty): A multicenter, pilot, clinical study. Ophthalmology 1998; 105:2082-90.

29. Damji KF, Shah KC, Rock WJ, et al. Selective laser trabeculoplasty vs argon laser trabeculoplasty: A prospective randomised clinical trial. Br J O phthalmol 1999;83:718-22.

30. Seider M I, Keenan JD, Han Y. Cost of selective Iaser trabeculoplasty vs topical medications for glaucoma A rch Ophthalmol 2012;130:529-30.

31. Stein JD, K im DD, Peck W W, Giannetti SM , Hutton DW . Costeffectiveness of medications compared with laser trabecul oplasty in patients with newly diagnosed open-angle glaucoma. A rch Ophthalmol 2012;130:497-505.

\section{ABOUT THE AUTHOR}

\section{Colin I Clement}

Glaucoma Unit, Sydney Eye Hospital, NSW, A ustralia; Central Clinical School, Faculty of M edicine, The University of Sydney, NSW Australia, e-mail: colinandkylie@me.com 